\title{
Victoria Hunter
}

\section{Embodying the Site: the Here and Now in Site-Specific Dance Performance}

\begin{abstract}
In this article, Victoria Hunter explores the concept of the 'here and now' in the creation of site-specific dance performance, in response to Doreen Massey's questioning of the fixity of the concept of the 'here and now' during the recent RESCEN seminar on 'Making Space', in which she challenged the concept of a singular fixed 'present', suggesting instead that we exist in a constant production of 'here and nows' akin to 'being in the moment'. Here the concept is applied to an analysis of the author's recent performance work created as part of a PhD investigation into the relationship between the site and the creative process in site-specific dance performance. In this context the notion of the 'here and now' is discussed in relation to the concept of dance embodiment informed by the site and the genius loci, or 'spirit of place'. Victoria Hunter is a Lecturer in Dance at the University of Leeds, who is currently researching a $\mathrm{PhD}$ in site-specific dance performance.
\end{abstract}

What is the relationship between the site and the creative process in site-specific dance performance?

What is the nature of the interaction between site, choreographer, performer, performance, and audience?

IN THE recent RESCEN seminar entitled 'Making Space', Doreen Massey challenged the concept of a singular, fixed 'present', suggesting instead that we exist in a constant process of producing 'here and nows' akin to 'being in the moment'. Throughout her address she referred to the concept of 'coevalness', pertaining to a simultaneous experiencing of spaces and places co-existing in time. This article is written in response to Massey's presentation, applying the concept of the 'here and now' to a recent site-specific dance performance, Beneath (2004), created as part of my practice-based $\mathrm{PhD}$ investigation into the relationship between the site and the creative process.

Throughout this article, Massey's 'here and now' $^{\prime}$ is discussed in relation to the concept of dance embodiment informed by the phenomenological interaction with the genius loci or 'spirit of place'. ${ }^{1}$ These concepts provide a framework for analysis of the various phases involved in the production of the performance work, exposing stages that I have called 'Experiencing the Site', 'Expressing the Site', 'Embodying the Site', and finally 'Receiving the Site' in the form of a performance work. These stages are discussed in a linear fashion representing a sense of progression 'through' the process whilst simultaneously reflecting a shift of focus from the choreographer-led early stages of the process through to the collaborative middle stages involving the performers, leading to an analysis of the final audience/performance interface. The term site-specific dance performance is defined as dance performance created in response to and performed within a specific site or location, where dance and movement are the dominant components as opposed to theatre- or installation-derived genres. $^{2}$

Beneath was performed in September 2004 in the basement of the Bretton Hall mansion building, ${ }^{3}$ an area normally inaccessible to the general public. Whilst involved in the creation of the work I became interested in the nature of the interactive relationship between the site, choreographer, performer, and audience. This paper explores the concept of embodiment as a symptomatic component of 
site-specific dance performance informed by an awareness of 'being in the moment' and resulting in a phenomenological exchange between site, choreographer, performer, performance, and audience.

Merleau-Ponty defines phenomenology as a 'study of essences' $(1962$, p. 5). In relation to the generation and performance of dance material, it can be considered as a bodily process whereby the individual experiences the site-phenomenon corporeally in an immediate process of 'transaction' with the site borne of being 'in the moment'. This process constitutes a conscious 'present' interaction with space and the world at large. Maxine Sheets-Johnstone describes the process thus:

Consciousness experiences its world and itself through its body. If we have conscious experiences, it is because our body moves within the environment as a spatial presence and intuitively knows the meaning of its spatiality.

(1979, p. 24)

My research attempts to interrogate the conscious sense of connection with the site experienced by myself and the performers throughout the creative process. This experience was informed and heightened by an awareness of being in the world comprising an embodied experience derived from being in the space. As opposed to addressing any mystical notions or interpretations of space and place, I want to consider phenomeno$\operatorname{logy}$ as an experiential phenomenon reliant upon the conscious presence of the individual in space, resulting in a human lived experience of that space.

Phenomenology, then, is applied to this investigation to refer to the body's lived experiences and interactions with the site, these experiences being embodied by the individual and transformed and expressed through the medium of dance. Valerie Preston-Dunlop (2002) provides a succinct definition of dance embodiment as 'a process which gives tangible form to ideas' (PrestonDunlop, 2002, p. 7).

In site-specific dance performance, then, the body gives form to ideas and responses to the site as experienced by the choreographers and performers ${ }^{4}$ (and latterly by the audience, as discussed later). This process occurs as a result of a heightened awareness of being in the moment during which the body becomes porous, open, and receptive. In the analysis of the practice-as-research investigation discussed here, the bodily experiencing and expressing of site is prioritized and placed at the centre of the investigation. As opposed to a dualistic approach, however, this discussion incorporates the notion of the thinking body. Space and place are experienced and expressed by a 'minded body, not a mind in command of something called body' (Horton-Fraleigh, 1987, p. 9).

\section{The Basement Project: Beneath}

If site-specific work makes any departure from the usual premise of theatre it is made out of a desire to let PLACE speak louder than the human mediator or actor who enters the place.

(Pershigetti, 2000, p. 9)

Pershigetti's reference to the human 'mediator' between the site and the site-specific performance appears particularly relevant to an analysis of my own role as a choreographer in this particular creative process. From the outset it was my intention to create a work that would exist in sympathy with the site, serving to 'reveal' the site to the audience as opposed to imposing my own artistic vision upon the site.

The work was created and performed in a section of the building containing several rooms which pre-production investigation revealed to be a disused wine-cellar fed by a long service corridor. Abandoned for many years, the space was unheated, covered in a thick layer of brick dust, and had become a haven for mosquitoes. However, despite these aspects, the site remained attractive to me as a choreographer involved in site-specific work. Whilst it contained many interesting architectural features, such as a vaulted ceiling, partial dividing wall, and a variety of doorways, all of which served to fuel the choreographic imagination, the site also appealed on a more fundamental, corporeal level. As for many site-specific practitioners ${ }^{5}$ the site in a sense 'spoke' to me in a phenomenological sense, informed by the genius 


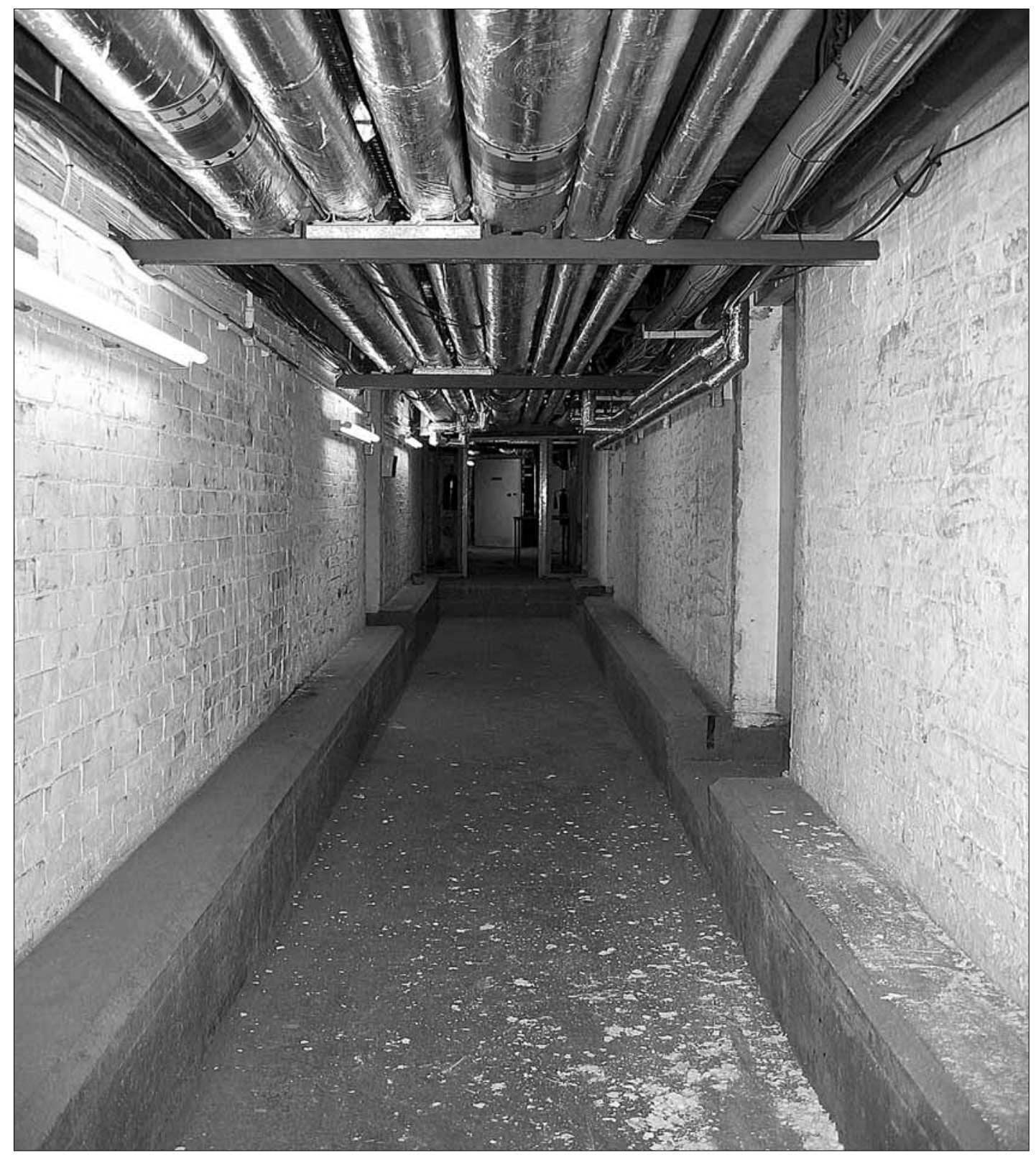

The basement site: the service corridor. Photo: V. Hunter.

loci or 'spirit of place' as defined by NorbergSchulz (1980).

In his work Genius Loci: Towards a Phenomenology of Architecture, Norberg-Schulz refers to 'Environmental Character which is the essence of place' (p. 7). This 'environmental character' combines with more formal spatial and architectural features to produce 'lived space' (p. 11) experienced holistically by the individual. Place then becomes 'a qualitative, total phenomenon which we cannot reduce to any of its properties' (p. 7).

This notion of 'lived space' experienced phenomenologically implies by its very definition an awareness of 'being' or 'presence' on behalf of the individual. Through a process of existing in the space, becoming present and receptive to the phenomenological essences encountered within the site, the individual 
absorbs and intuits the site at a fundamental level. Disused or abandoned sites, however, inevitably carry with them a sense of the past pertaining to the lives of the previous occupants and/or the former usage of the site. These resonances may be informed by factual information discovered through pre-production research (as in the Beneath project) and/ or by architectural/functional components remaining in situ.

The lived space of place then becomes informed by the individuals' awareness and presence in the space in the here and now combined and negotiated with an awareness of the past. This process then relates to Massey's notion of place as an 'event' informed by an 'intersection of trajectories'. ${ }^{6}$ In the basement site the trajectories of past and present combine to create the genius loci or 'spirit' of place. If, according to De Certeau, 'space is a practised place' (1984, p. 117) then this particular space had been practised, performed, inhabited, and transformed many times over. Cathy Turner suggests that this process results in a 're-writing' of space:

Each occupation, or traversal, or transgression of space offers a reinterpretation of it, even a rewriting. Thus space is often envisaged as an aggregation of layered writings - a palimpsest.

(Turner, 2004)

The palimpsestic nature of the basement site then appeared to leave a resonance of past lives, narratives, and, less explicitly, energies equating to the genius loci or 'spirit of place' and began to inform my own subjective experiencing of the site in the here and now. Whilst avoiding any literal anthropomorphizing of the site, these qualities came to be referenced during the rehearsal process as the energies, resonances, and past lives of the site resulting from my own phenomenological experiencing.

Whilst seeking to expose the methodologies and approaches contained within the process, this particular observation serves to

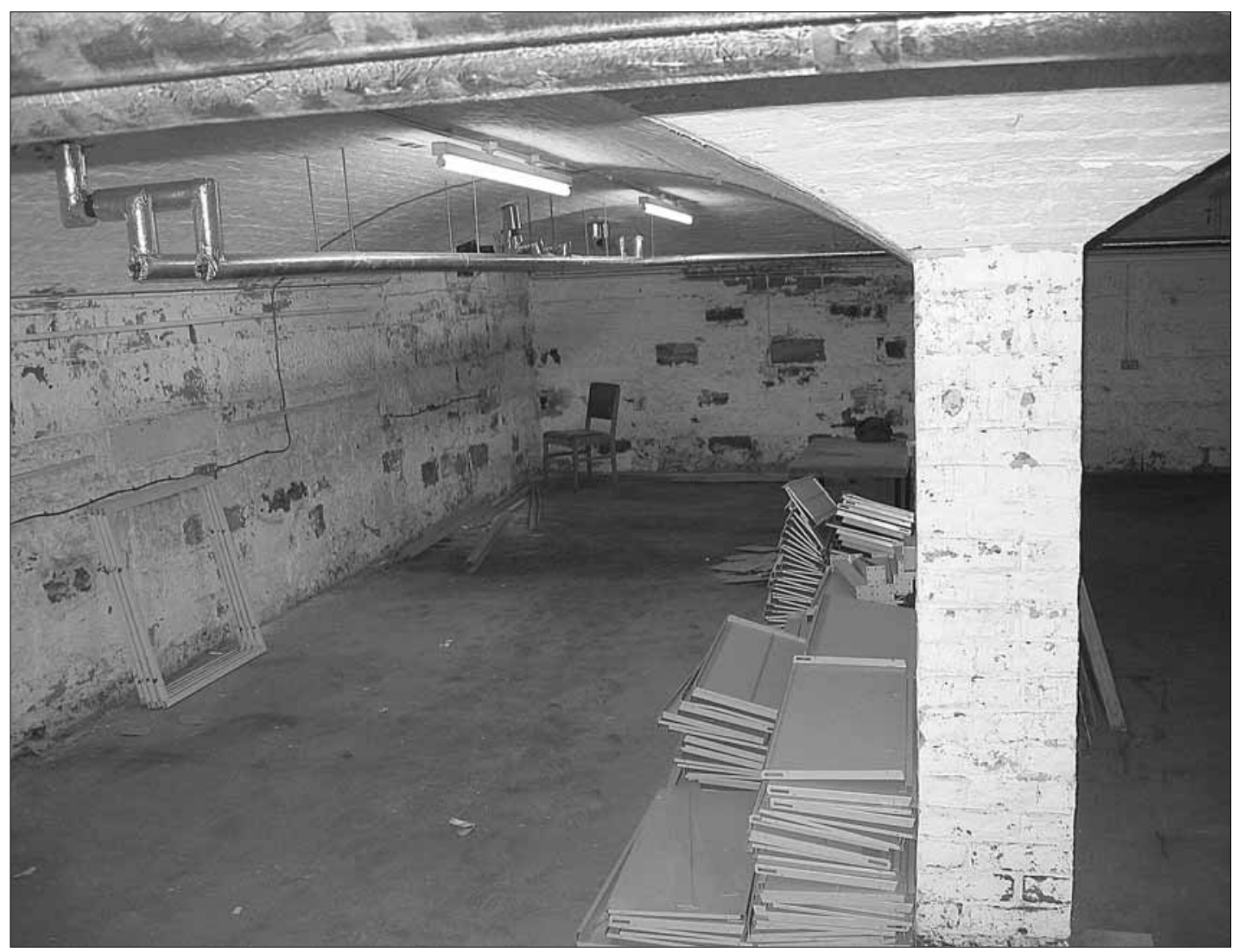

The basement site: the vaulted wine-cellar. Photo: V. Hunter. 
highlight the problematic nature of objectifying the subjective experience. The inadequacies of language as an expression of the phenomenological are exposed here through an attempt to verbalize and label a uniquely personal experience. The description of 'lives, energies, and resonances' contained within the site reflects only a fraction of the holistic, whole-body, sensorial interaction with the site experienced by myself, and later by the performers. The multitudinous nature of the phenomenological experience can often render these experiences unutterable in verbal form. Mike Pearson refers to this dichotomy when discussing the documentation of performance practices and experiences:

Their embodiment in sensoria raises the issue of the representation of phenomena which are partially, at least, ineffable - beyond language.

(Pearson, 2001, p. 57)

As a result, movement actions, imagery, sound utterances and physical demonstration were utilized as accompanying embellishments to verbal descriptions when attempting to communicate and share phenomenological responses between myself and the dancers and vice versa.

\section{Experiencing the Site}

Akin to Mike Pearson's approach in Theatre/ Archaeology (2001) the site-specific choreographer experiences and interacts with the site on a number of levels, metaphorically digging beneath the surface to reveal a uniquely personal interaction with the site. On an immediate, practical level the site presents the choreographer with a range of spatial information, elements of which may serve to inform the creation of movement material and choreographic form.

Theories of experiencing space drawn from Lawson (2001), Lefebvre (1974), and Tuan $(1974)^{7}$ offered a theoretical framework for the practical investigations embedded in the project whilst simultaneously raising my awareness as a choreographer of the potential scope of spatial information contained within the site. My initial investigation into the site therefore adopted a formalistic approach addressing the architectural and the spatial qualities of the site. Pre-production research involved the collection of written and oral histories of the site, the study of floor plans, and a guided tour of the site.

This formal architectural and spatial information combined with historical and contextual information concerning the former inhabitants of the building and the past function of the site to suggest an immediate choreographic response. This response consisted of the imagined creation of an organizational structure for the dance, commencing with a solo introduction to the space followed by a group dance section contained within the larger wine-cellar room. This resulted in the preparation of a 'story board' (below) detailing the organizational form of the opening and initial section of the final performance work.

On closer inspection, however, whilst the site's formal qualities and sense of dynamic 'flow' ${ }^{\prime}$ appeared to provide an indication of the final performance form and structure, ideas and suggestions for movement content remained elusive. An over-emphasis on the

\section{$14 / 7 / 2004$}

- Associations of abandonment, closed, shut-down, cold, empty shell.

- Main location - corridor leading to wine cellar, associations of usage, wine cellar, wine bottles, servants.

- Corridor, ante-room, main space implies a natural progression of form from solo group material.

- Initial 'storyboard' suggested by the form of the space.

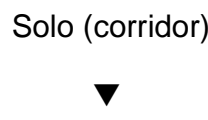

Ante-room (installation)

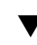

Wine Cellar

Choreographic diary entry, 14 July 2004. 
site's formal, spatial, and factual components in the first instance had in fact resulted in an unintentional attempt effectively to colonize the site through the application of an imposed form lacking in substantive meaning.

I had in fact prejudged the site in an objective manner, revealing perhaps the dichotomy between practice and academic research. As a result, any attempt to generate movement content appeared futile and insubstantive. In the early stages of the production process the actual practice as research began to reveal its own research methodology borne from the practice itself as distinct from an assumptive academic approach. Through a negation of the corporeal phenomenological experiencing of the site I was in danger of overlooking a vital component in the creation of a site-specific dance performance.

Clearly, an embodied approach involving the body-in-space was required. In an attempt to experience the site in a less contrived manner I allowed myself time just to enter the space alone and simply 'be' in the space in a series of 'moments'. This would involve me moving slowly through the space, for example, touching, sensing, and experiencing the space, or simply sitting quietly absorbing the atmosphere around me. Maxine Sheets-Johnstone situates this type of approach at the heart of the phenomenological experience:

The phenomenologist's attitude towards the phenomenon is neither objective or subjective, but rather an attitude of being present to the phenomenon, fully and wholly.

(1979, p. 12)

Undoubtedly, in this context I was entering the space with a heightened sense of awareness informed by the intention of the project and the intention of the exercise itself. However, the intention of the exercise remained to attempt to experience the site-phenomenon fully and wholly. The following journal extract records one of the responses to the site generated during this exercise:

Abandoned, cold, shut down, an empty shell. Flickering light beneath the surface, resonances, energies.

(Choreographic diary entry, 20 July 2004)
This exercise proved invaluable in the facilitation of a corporeal exchange between individual and site. Through simply 'being' in the site an inside/outside interface ${ }^{9}$ began to occur, invoking an awareness of the site's phenomenological 'essences'. Through this investigation, my developing awareness of the site equated to an initial process of tuning in prior to any form of interpretation or analysis. The site is experienced by allowing the body-self to absorb phenomenological experiences of the site and the genius loci in the moment. In light of these theories, is it possible to objectify and/or conceptualize what I was actually experiencing?

\section{An Interplay of Responses}

The outcome of the experiential exercise described here is referred to as an exchange or interface, thereby implying a two-way interaction between the site and the individual. Indeed, simply by entering the site the individual's presence constitutes an intervention within that site. This notion of intervention or disturbance becomes particularly pertinent when discussing the creation of work in disused or abandoned sites. As previously discussed, the site offers up a wealth of visual, spatial, historical, and factual information for the explorer. But it is only through bodily interaction and intervention that the site's phenomenology and genius loci are revealed.

Norberg-Schulz's description of the genius loci as 'lived space' comprises two interrelated components of 'space' and 'character'. Space, according to Norberg-Schulz, denotes the 'three-dimensional organization of the elements which make up place', while 'character' refers to the 'general atmosphere which is the most comprehensive property of any place' (1980, p. 11). Norberg-Schulz proposes that these two elements are interrelated and operate in a co-operative manner to produce the genius loci or 'spirit of place'. This identification of the formally tangible and intangible aspects of place equates to my own investigations into the basement site.

As the practical investigation developed it became clear that my experiencing of the site 
and the subsequent generation of movement material was informed by a complex interplay of responses resulting from interaction with both its formal/architectural and the intangible/atmospheric components. This combination invoked a unique phenomenological response. The responses then combined with information gathered from the pre-production research period regarding the past usage, inhabitants, and 'life' of the site, and began to shape and influence my creative thinking.

Notions of past lives, energies, and resonances of the past began to emerge as key themes, serving to provide a framework and conceptual structure in which to house the wealth of phenomenological responses generated by myself and the performers. Whilst these energies and resonances served to provide a structure and direction for the creative work, the intention was never to attempt to recreate a snapshot of the past akin to a modern-day costume drama. Instead, the theme and notions of the past were explored in relation to their impact upon the individual's experiencing of the site in the here and now.

Any likelihood of romanticized nostalgia was lessened as these resonances of the past became associated by myself and the performers with notions of abandonment, sadness, and neglect. The two trajectories of past and present became located in the site creating a 'meaningful place' as defined by NorbergSchulz (1980, p. 7).

\section{Expressing the Site}

How were these experiences transformed into dance performance?

Once the pre-production and experiential research stages had been completed, the project was able to shift into a process of 'expressing the site', involving the formulation of research data into dance responses to express the performers' and choreographer's experiences. The choreographic intention remained from the outset to create a work which revealed the site, retaining a sense of connectivity between the site and the emerging work at all times. To this end, rehearsals took place on location, with the intention that the work would develop in a process of negotiation and collaboration with the site.

The work involved seven dancers (five female, two male), and the project adopted a devised creative approach involving a collaboration between the choreographer and the performers. The nature of the interplay between the phenomenological responses to components of the site's 'space' and its 'character' and the generation of both dance form and content became apparent throughout the rehearsal process. For example, the opening and initial sections of the dance retained elements of the original 'storyboard' ideas (see page 371 ) suggested by the formal architectural and spatial relationships contained within the site. However, movement content and qualities contained within these episodes began to emerge in response to phenomenological information.

The dancers were invited to improvise movement in response to their sensory, phenomenological, and kinaesthetic experiencing of the site. The purpose of this exercise was to reveal and explore the performers' corporeal responses, thereby focusing on the 'otherness' of response as opposed to the visual or verbal. In addition, this type of devised, collective exploration of site served to combine with my own responses, thereby broadening the resource of response to the site-stimuli. The following diary extract provides a description of some of the movement content generated during this initial improvisatory phase:

Twisting, touching the body, touching the walls. High-arch movements beginning to appear, arms raised to the ceiling whilst body curves over. Sinking, curved body, curved arms. Sliding of feet, turning and dropping, suspending and dropping, delicate.

(Choreographic diary entry, 9 September 2004)

These movements were observed and recorded during the opening moments of the exercise and can clearly be related to the dancers' response to the architectural components of the site's curved ceiling and arched brick-work (see photo on page 375). However, as the improvisation continued, a selection of 
more recognizable, familiar movement material began to emerge, perhaps indicating a diminishing concentration and associated connection between the dancers and the space. As a result, only a few of the most 'genuine' responses were retained, these largely generated in the first moments of the exercise. ${ }^{10}$

What interested me most as a choreographer was the dynamic quality contained within the dancers' movement responses and the commonality of these dynamic siteresponses. These responses comprised a combination of soft, flowing, gentle qualities and more sudden, sustained moments. Somehow this level of response appeared to contain the most honest corporeal reaction to the site, paralleling the energies, essences, and dynamics of the site itself. ${ }^{11}$ These responses felt spontaneous, unplanned, and unencumbered by elements of the dancers' inherited codified dance technique and aesthetic elements.

In this sense, these responses could be equated to an embodied experiencing of the site manifested through movement, evidencing a phenomenological response. Referring back to Sheets-Johnstone's consideration of 'presentness', these dynamic responses can be equated to a phenomenological response which is neither objective or subjective, borne of being in the moment and open to the here and now of the site phenomenon.

Could this very 'present' state of being, comprising a heightened state of phenomenological awareness, be equated to a 'hyperplace' of 'presentness'? This particular place is 'practised"12 in the moment, however; as opposed to implying an indication of stability' (a defining component of place according to De Certeau), it is reliant upon a degree of fluidity and flux. This conceptual place then moves above and beyond conventional definitions of place, becoming a 'hyper-place' situated in the transitory 'here and now'.

Through a process of experiencing situated in this hyper-place, requiring the minded body to respond honestly and unquestioningly to the site-phenomenon, it could be suggested that the dancers had revealed the site's underlying energies and qualities, thus creating an immediate and dynamic response in the body. The Beneath project, then, began to call for a different movement approach, challenging my usual choreographic vocabulary as applied more frequently to a traditional theatre context. 'Theatre dance' ${ }^{13}$ vocabulary appeared incongruous in this site, artificial and unrelated to the genius loci or 'spirit' of the place.

\section{The Site as Choreographer}

This incongruity could perhaps be related to the concept of intention in site-specific performance. 'Theatre dance' vocabulary by its very definition is created for performance within a very specific environment encompassing a range of spatial and presentational codes and conventions. The performance material in this context is housed and framed within the theatrical environment, but does not usually bear any conceptual relationship to the theatre building in which it is housed. A very different intention and relationship between content and environment forms a key component in site-specific dance performance, as Eileen Dillon observes:

Movement that is borne out of a sensory response to environment draws an audience's attention as much to the environment as to the performer.

(Dillon, 1988, in Wrights and Sites, 2000)

In accordance with my intention to 'reveal' the site, only movement content generated from a direct response to the site appeared to function effectively in this sense, and any suggestion of artifice or gratuitous embellishment of movement was eradicated from the final work. ${ }^{14}$ The movement aesthetic thus began to develop an informal, pedestrianderived quality, devoid of any discernible reference to a codified technique.

One such movement phrase involved a reaching gesture whereby the dancer's hand would touch the air and play with its texture between the fingers. This movement resulted from my direct response to the dusty, damp atmosphere contained within the site, which at times appeared 'tangible'. This arm gesture was developed by the dancers and later combined with a simple walking pattern, allowing them to sample the atmospheres at different points in the space. The lack of 


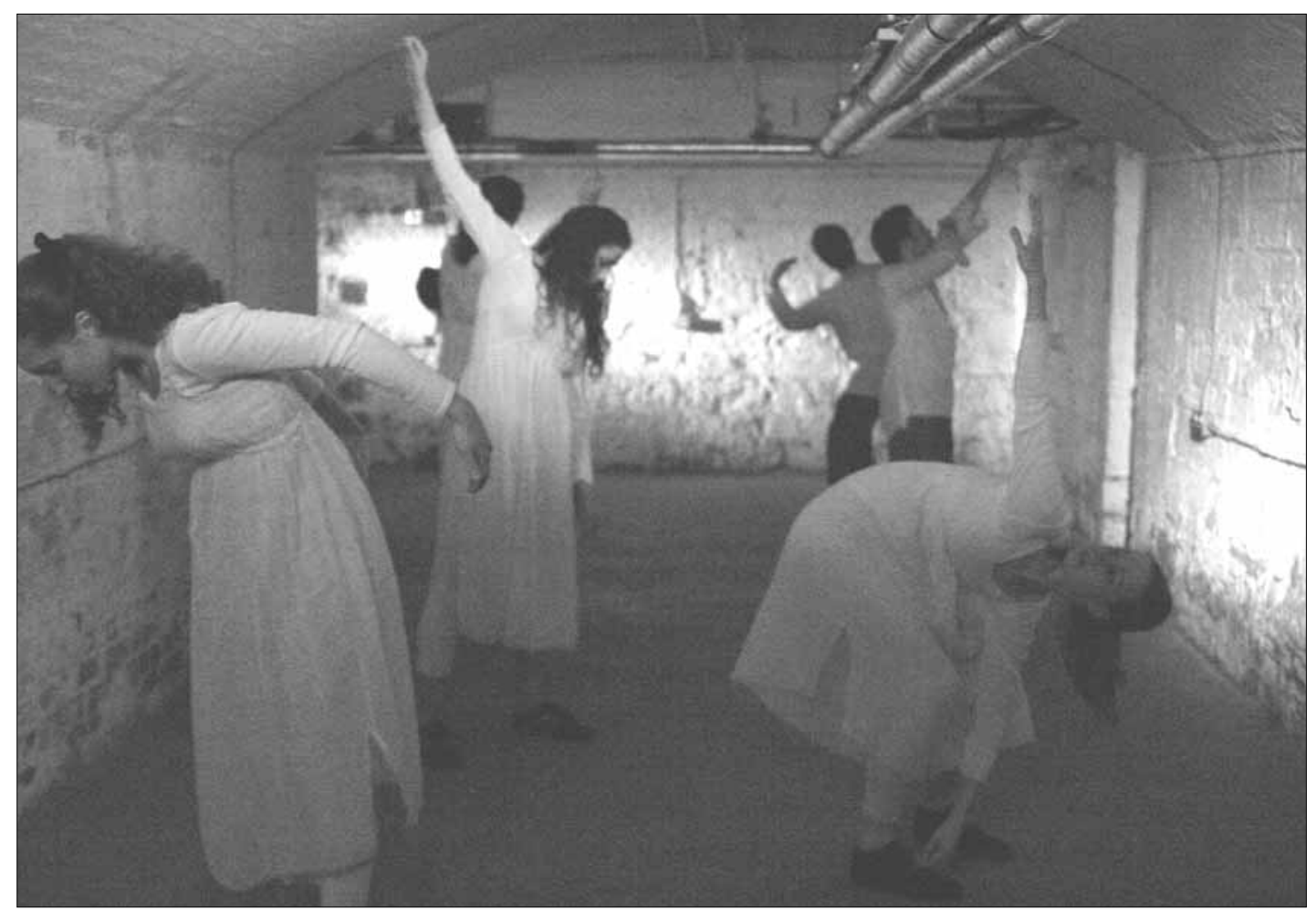

'The dancers' response to the architectural components of the site's curved ceiling and arched brick-work.' Photo: P. Davies.

'theatricality' helped me to facilitate a sense of balance between the site and the work as the developing movement content began to reveal a through-line of connectivity with the site, thereby lessening any degree of incongruity.

The site in a sense had begun to choreograph the choreographer, calling for a particular movement approach and drawing my aesthetic and artistic attention towards particular architectural and spatial features which could not be ignored. These included the presence of a central dividing wall which began to operate as a choreographic device in its own right, as movement sequences incorporating touching, leaning, running, and rebounding into the wall began to develop. Similarly, linear floor patterns traversing the space began to develop in response to the shape of the site and the dynamic qualities that appeared to resonate in the space when inhabited by moving bodies.

Following a prolonged period of time spent in the space during the rehearsal and devising process, a form of osmosis between the site, the choreographer, and the emerging work appeared to develop, largely due to the constant process of referral to and inclusion of the site-stimuli involved in this particular creative process, which began to reveal that, unlike in traditional studio-based approaches to dance-making, the ever present site stimulus necessitates a constant process of review and, to a certain degree, self-censorship.

In accordance with Pershigetti's consideration of the artist as 'mediator' in this context, then, the choreographer must remain mindful of maintaining a balance between intention and aesthetic impulse, ensuring that the work develops in collaboration with the site as opposed to imposing itself upon it.

\section{Embodying the Site}

If embodiment is used in this context to refer to a process whereby the human body gives 'tangible form to ideas', 15 then the intention of the dancers and the dance in the Beneath 
project was to give form to ideas and responses arising from an interaction with the site. As previously discussed, movement content, form, and dynamic qualities began to emerge through an organic process of experiencing and communing with the site. Once captured both bodily and more formally through the use of video recording, these initial responses became formalized into structured movement sequences or episodes, as referred to throughout the rehearsal process.

Initial movement responses generated through devising episodes as previously described would be developed through the application of choreographic devices ${ }^{16}$ and group relationships, while movement sequences devised in response to my own experiencing of the site would be taught to the dancers and further modified or embellished in order to achieve an appropriate sense of 'fit' between the site and the developing work.

During rehearsals, the focus of the project began to shift from a process of collecting and collating experiences and responses to the site to one of embodying these responses by giving form to them through the bodily medium of dance. The term 'embodiment' is used to refer to the performer and the dance as the medium of expression and their capacity to embody the site's essences in a phenomenological sense. In conventional creative performance processes, contained within a studio setting, the rehearsal and refining process, with its necessary shift of focus towards the concretization of an end product, can result in the performers becoming distanced from their initial response to a particular stimulus. However, in site-specific dance performance the potential for this process of detachment is lessened due to the omnipresent nature of the surrounding sitestimulus.

Nevertheless, during the Beneath rehearsal process there remained the potential for the dancers to become over-familiar with the developing dance material during the rehearsal process, resulting in a lack of connection with the site and the original choreographic intention. In an attempt to perfect the aesthetic qualities of the movement content, the performers had reverted back to a conven- tional mode of performance preparation, resulting in the production of an associated conventional, theatrical performance style.

As a consequence of this, the original phenomenological responses and essences of the work became diluted. Once this began to occur the work developed a degree of incongruity, appearing disconnected from the site. This particular site-specific dance performance therefore demanded a different approach to performance in addition to the different approach to movement creation as discussed earlier.

As a choreographer, I became particularly aware of the inappropriateness of any attempt at artifice or acting by the dancers whilst performing the work. This concern operated on two levels: firstly, as the basement site was a relatively small and intimate space, the dancers and audience members would be in close proximity, thereby lessening the need for any overt acting or projection; secondly, the movement vocabulary created had successfully managed to capture and develop a sense of connection to the site through both actual movement content and dynamic components. This delicate relationship could all too easily have been destroyed through the application of an unsympathetic performance persona.

In an attempt to develop this complete embodiment of the site, the dancers were encouraged to re-connect with the site, and so to develop a whole-person, thinking-body approach. Once the dance work had been choreographed and established in the dancers' movement memory, each performer was encouraged to spend a period of time remembering and 'revisiting' the site in relation to the movement material and the original motivation behind its creation. The dancers were encouraged consciously to see the walls as they brushed past them, feel the floor as they touched it and sense the site's atmosphere and its effect upon the skin receptors.

Following the rehearsal session the dancers were asked to record their responses to the exercise, and the following questionnaire extract provides an insight into the dancer's reflection upon the task: 
I tried to be everything I was doing, I had to stay in the 'now' and be true to what I was experiencing.

(Performer questionnaire response, Beneath, September 2004)

This process not only influenced the dancers' creation of a performance persona, but also served to enrich the process of dance embodiment. Through this process, the siteperformer connection began to operate on two levels, as the dancers performed movement material created during the rehearsal process whilst simultaneously constructing and presenting a performance of that material informed by a real-time awareness of the body-self in the site existing in the here-andnow moment of performance.

Through this process, then, the dancer experiences an epistemological and ontological interface with the site and its essences, occurring through a corporeal interaction with the space manifested through the medium of dance performance.

\section{Receiving the Site}

If the site-specific dance performance constitutes an embodiment of site through the medium of dance, then could it be suggested that an audience member effectively receives the site through the site-specific dance performance? If so, what does the audience experience and how?

Theories concerning the experiencing of space and place are well documented by authors including Lefebvre (1974), Lawson (2001), and Bachelard (1964), who identify the complexity of this relationship. Sensory, cognitive, spatial, ideological, and psychological factors are amongst those elements which combine to create our perception of space and place, and can be seen to explain why space and spaces can be experienced in many different ways.

As previously discussed, the act of simply entering a space engages us in a process of interaction or 'transaction', ${ }^{17}$ with our spatial environment during which an inside/outside interface occurs. The site-specific audience member does not approach the performance and the site in an arbitrary, passive manner, arriving instead armed with a wealth of personal and contextual information serving to inform their experiencing of the site and the performance work. ${ }^{18}$ Similarly, the audience member does not receive an impartial, neutral experience of the space. In sitespecific performance the site is altered by the presence of the performers and the choreographer's intervention in the site and the work itself.

It could be suggested, then, that the audience does not in fact experience the true site but instead experiences the ephemeral place of performance. In reference to Massey, this 'place' of performance comprises a number of personal, artistic, social, spatial, and contextual 'trajectories' which converge 'in the moment' of performance. The degree to which the artistic intervention/interaction with a site occurs can vary dramatically from performance to performance, depending upon the production and the choreographic intention. The Beneath project, for example utilized lighting, costumes, and musical accompaniment to enhance the performance and accentuate particular qualities and elements of the site.

The intention was not gratuitously to impose theatrical convention upon the site, but to utilize these components to enhance the choreographic intention, thereby revealing those elements of the site which had 'spoken' to me initially. Through highlighting these elements and accentuating their qualities, the audience's response to the site and the work became potentially guided by the choreographer. These responses, however, remained connected to the audience's visual and aural perceptions. An analysis of a more fundamental experiencing of the site-specific place of performance can be achieved through a discussion of the audience in the site and their phenomenological experiencing of the place of performance.

\section{Engaging the Audience}

By its very definition, site-specific performance challenges accepted codes and conventions regarding the presentation and the reception of performance work. Through the 


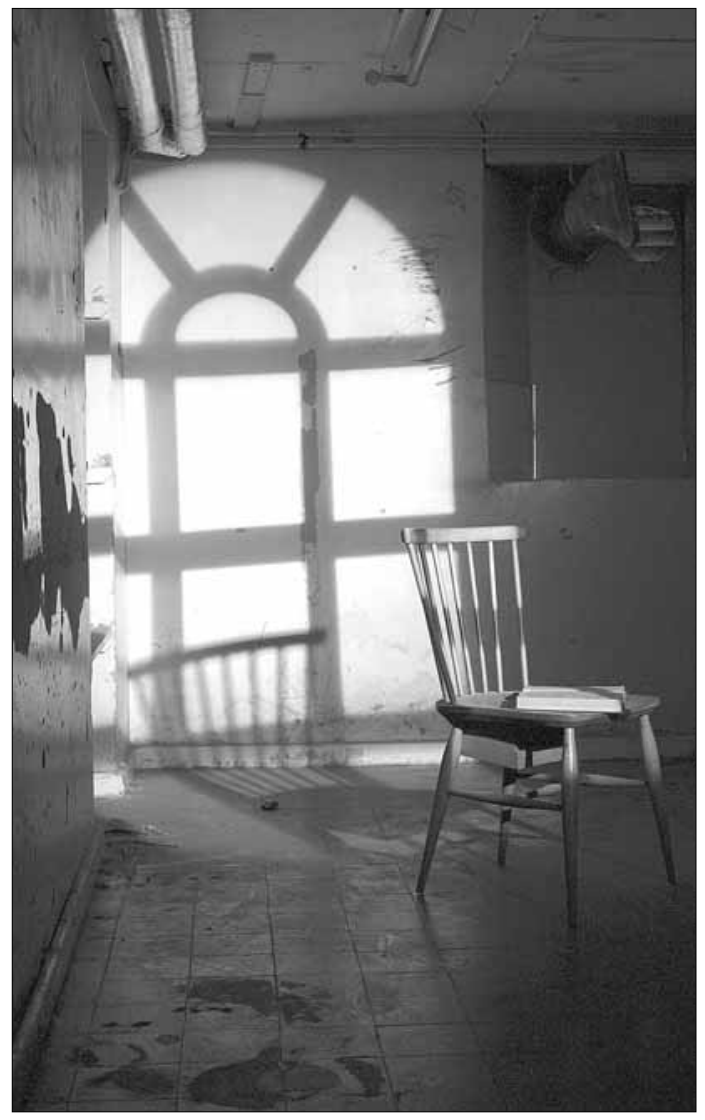

'A single chair placed in the corner of the space, lit by a single lamp.' Photo: P. Davies.

rejection of the traditional black-box theatre, site-specific performance engages the audience in a more immediate manner. The audience member exists in the space with the surrounding work, thereby responding and participating in and with the work in an upclose phenomenological exchange as opposed to 'receiving' ${ }^{19}$ the work from a distance.

In the Beneath project, the potential for this type of phenomenological interaction was facilitated from the outset. Upon entering the subterranean site, the fifteen audience members stepped into a constructed 'world' comprising a walk-through pre-performance installation situated in a disused laundry room. This room contained a single chair placed in the corner of the space, lit by a single lamp; an old book was placed on the chair suggesting an absent presence (see photo above). Audience members walked past the installation prior to descending a further staircase which led into the main performance space, whilst a dripping tap situated within the disused laundry space provided the sound accompaniment for this journey.

The intention of this installation was to facilitate the audience's transition from the everyday experience of the outside world to the world of the basement location, thereby assisting a gradual shift in consciousness and awareness. This process of physically moving through the space also allowed the audience time to absorb and experience the space at a corporeal level prior to any experiencing with the dance work itself.

Once the performance began, however, the audience embarked upon a process of experiencing the ephemeral place of performance. The audience's experiences were captured through post-performance questionnaires and group interviews and discussions. In addition to responses detailing descriptive recollections and interpretive readings of the work the questionnaires and subsequent audience interviews revealed responses pertaining to less tangible, more elusive experiences of the work. Typical responses included:

I felt I had gone back in time to another period. I saw beauty in the movement and various energies throughout the piece.

I felt a desire to be involved - closeness. Changing feelings - empathy, sadness, then surprise.

These types of responses allude to a range of emotional and sensory reactions to the work, serving perhaps to exemplify the 'other-ness' of response which is elicited by the dance medium.

Many audience members appeared to find these responses difficult to articulate effectively, as they struggled to give verbal form to a variety of corporeal, sensory, and kinaesthetic responses. These particular responses, then, appeared to co-exist with more formalized interpretations of the work, serving to inform a phenomenological experiencing of the work. These descriptions of phenomenological responses appeared to spring from corporeal resonances experienced by audience members in the moment of performance: 


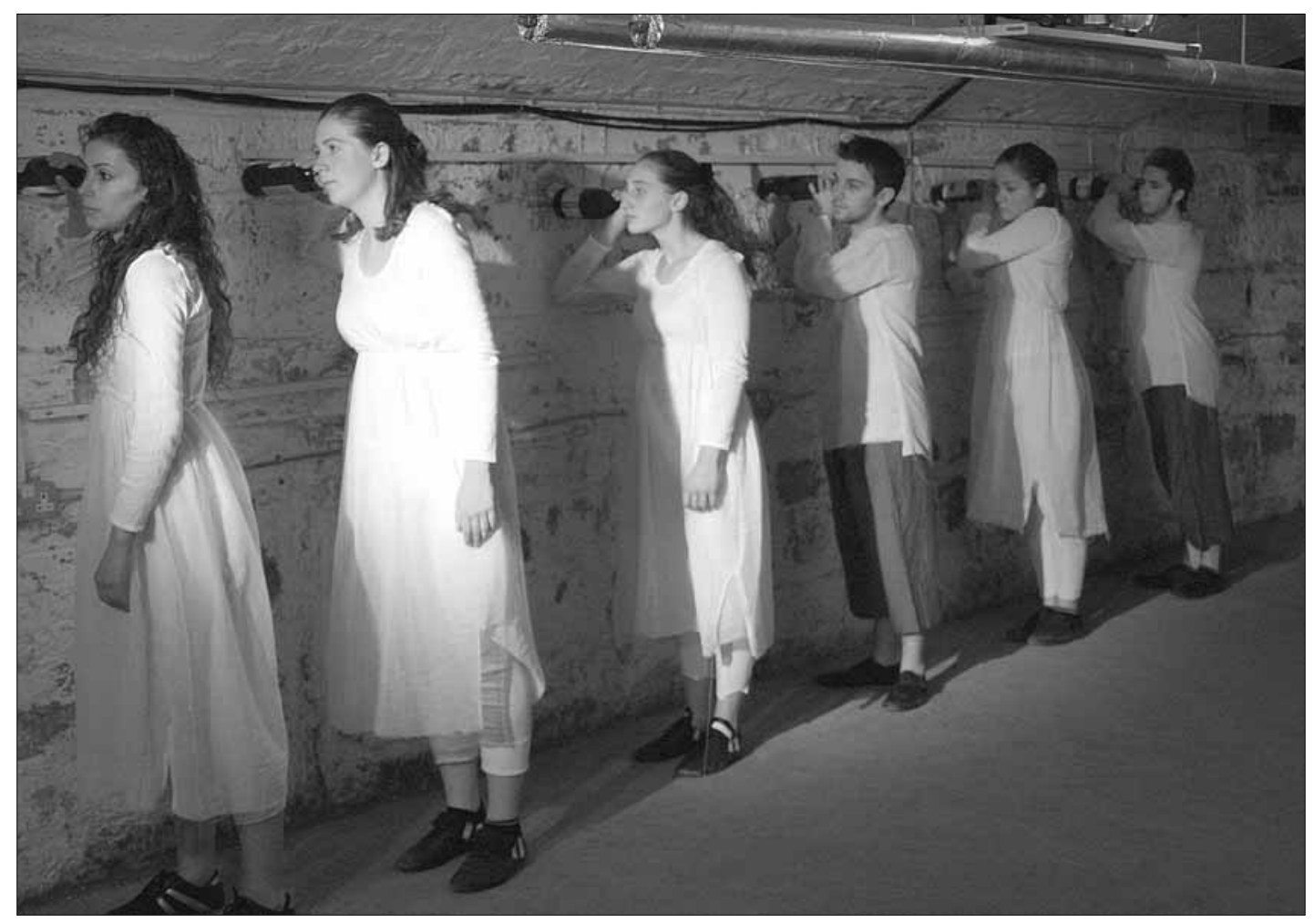

You almost felt yourself moving with them [the dancers] and dancing with them. A real sensory experience.

The sensitivity of the dancers made me sensitive towards them and aware of their actions.

These responses equate to theories of dance phenomenology which propose that the audience member receives the dance in a corporeal manner. The performer and audience enter into a bodily 'exchange' based on a shared knowledge of corporeality. HortonFraleigh refers to the phenomenon thus:

I dance the dance with the dancer, enact it, dissolve it and take it into myself. In this sense, I also embody the dance.

$(1987$, p. 62)

Horton-Fraleigh proposes here that the audience then embodies the dance. If, as previously discussed, the dancer embodies the site through giving form to ideas of the site, could it logically follow that the audience's embodiment of the site-specific dance also constitutes an embodiment of site? Is it plausible to suggest that as a bodily art form site-specific dance performance has the potential to create a more authentic through-line of connectivity between the site phenomenon and the resulting performance work than other site-specific genres, which may rely on the aural, verbal, and/or visual as their primary mode of expression?

If so, through the dance's embodiment of site the audience member can experience the site/work phenomenon on a fundamental, corporeal level, enabling the individual to access a different type of knowing based on whole-bodily experience. Through acknowledgement and acceptance of this phenomenological exchange, the audience member begins to experience and participate in the site-specific dance responding bodily to the phenomenology contained within the place of performance.

\section{Conclusion}

Informed by Massey's questioning of the nature of the 'here and now', I have hoped to reveal in this analysis of the Beneath project a commonality of concern for an awareness of 
'presence' throughout the various stages of the creative process. The creative processes employed when experiencing and interacting with the site and the work itself required the individuals involved to be wholly present in the space, engaged and aware of the transactions occurring in the moment. As identified here, this particular site and location contained a particularly tangible 'spirit' of place or genius loci and a wealth of phenomenological energies and resonances. These elements of the site necessitated a very present, open, and aware approach to experiencing and developing site-responses into embodied dance performance.

The concept of the 'here and now' in sitespecific dance performance can be explored through the various stages involved in the creation of the work. Throughout, the choreographer's relationship with the site evolves and develops through a process of negotiation informed by a developing sense of familiarity and associated osmosis. From the initial stages of experiencing the space presently, responding to the here and now of the initial moment of interaction, through to the creation and formalization of movement material based upon these responses, the choreographer shifts from a position of 'being in the moment' to re-creating a resonance of the 'there and then'.

At this stage of the process the formalization of these phenomenological responses into movement material could be viewed as an attempt to objectify the subjective. The dance form in this sense acts as a form of documentation of the body's corporeal, phenomenological interaction with the site. Unlike with literary documents, however, due to the porous nature of this corporeal interaction the dance document remains subject to a continuous process of rewriting informed by the nature of the transaction between individual and site.

Once engaged in the rehearsal process the performers seek to renew and refresh the work and their performance of the work by importing their own 'presentness', stemming from their conscious awareness and actual presence in the space whilst rehearsing. Similarly, the final performance outcome presents a collaboration between the choreographed 'there and then' and the performers' 'here and now', as their actual real-time lived experience of the site feeds into the performance on a moment-by-moment basis. The embodied work is then absorbed by audience members while they are simultaneously engaged in their own corporeal experiencing of the here and now resulting from being in the place of performance.

In accordance with Massey's notion of 'coevalness' the final resonances of the site, the work, and the ephemeral place of performance are internalized and carried with the audience members, consigned to memory and surfacing occasionally as a remembered 'there and then' in a series of future 'here and now' moments.

\section{References}

Bachelard, G. (1964), The Poetics of Space (New York: Orion Press).

Blom, L., and Chaplin, L. (1989), The Intimate Act of Choreography (London: Dance Books).

Bloomer, K. C., and Moore, C. W. (1977), Body, Memory, and Architecture (New Haven: Yale University Press).

Ching, F. D. K (1996), Architecture, Form, Space, and Order (New York: Wiley).

De Certeau, M. (1984), The Practice of Everyday Life (University of California Press).

Hall, M. and E. T. (1975), The Fourth Dimension in Architecture: the Impact of Building on Behaviour (Santa Fe, Mexico: Sunstone Press).

Horton-Fraleigh, S. (1987), Dance and the Lived Body: a Descriptive Aesthetics (University of Pittsburgh Press)

Kaye, N. (2000), Site-Specific Art: Performance, Place, and Documentation (London: Routledge).

Koplowitz, S., www.webbedfeats.org (accessed 3 June 2003).

Lawson, B. (2001), The Language of Space (Oxford: Architectural Press).

Lefebvre, H. (1974, trans. D. Nicholson-Smith, 1991), The Production of Space (Oxford: Blackwell).

Lynne-Hannah, J. (1983), The Performer-Audience Connection (University of Texas Press).

Norberg-Schulz, C. (1980), Genius Loci: Towards a Phenomenology of Architecture (London: Academy Editions).

Pearson, M., and Shanks, M. (2001), Theatre/Archaeology (London: Routledge).

Pershigetti, Simon, 'Site-Specific: The Quay Thing Documented', Wrights and Sites, Studies in Theatre and Performance, Supplement, No. 5 (August 2000).

Preston-Dunlop, V., and Sanchez-Colberg, A. (2002), Dance and the Performative, a Choreological Perspective: Laban and Beyond (London: Verve.)

Seager, W. (1999), Theories of Consciousness: an Introduction and Assessment (London: Routledge).

Sheets-Johnstone, M. (1979), The Phenomenology of Dance (London: Dance Books). 
Smith-Autard, J. (1976), Dance Composition (London: Lepus Books).

Tuan, Y. F. (1974), Topophilia: a Study of Environmental Perception, Attitudes, and Values (New Jersey: PrenticeHall).

Tuan, Y. F. (1977), The Perspective of Experience (University of Minnesota)

Turner, C., 'Palimpsest or Potential Space? Finding a Vocabulary for Site-Specific Performance', New Theatre Quarterly, XX, No. 4 (November 2004).

Wrights and Sites, ed. (2000), 'Site-Specific: The Quay Thing Documented', Studies in Theatre and Performance, Supplement No. 5 (August 2000).

\section{Notes}

1. See Norberg-Schulz (1980).

2. Recent examples of this type of work include Genesis Canyon (1996), choreographed by Stephan Koplowitz, performed at the Natural History Museum; and Salome (1999), created by Suzanne Thomas for Seven Sisters dance group, performed at St Pancras Chambers, Kings Cross, London. This type of work is inspired by and dependent upon its location and differs from siteadaptive work, such as Siobhan Davies's Plant and Ghosts (2002), whereby a preconceived work may tour to a variety of unconventional spaces Whilst these spaces share similarities in their unorthodoxy as performance venues, such works cannot be deemed 'site-specific' in the true sense of the word, since the essence of the work remains constant from location to location.

3. The mansion dates back to the eighteenth century and currently houses the University of Leeds School of Performance and Cultural Industries.

4. This article refers to a devised, collaborative approach to dance-making as employed within the creation of Beneath, September 2004.

5. Geraldine Pilgrim (Corridor Company) discussed the nature of this type of interaction with sites, during an address at the Site/Source/Resource symposium, University of Exeter, September 2004. See also Eileen Dillon's documentation of her performance work Absent Water in Wrights and Sites (2000).
6. Doreen Massey, paper presented at RESCEN Seminar 'Making Space', RIBA, London, 12 January 2005.

7. These theorists examine space and the concept of the production of space from both subjective and objective perspectives.

8. The term here is used in relation to the architectural concept of anthropometry and dynamic 'fit'. See Ching (1996), p. 312.

9. See Lefebvre (1974)

10. The use of the term 'genuine' here refers to my own choreographic and artistic value judgement on the emerging work determined by my artistic intention and personal preference.

11. See Ching (1996)

12. See De Certeau (1984).

13. 'Theatre dance' is defined here as dance performance created for performance within a conventional theatre setting. This type of dance may employ a codified dance vocabulary and may employ conventional approaches towards issues of projection and presentation to a distanced audience.

14. This could be suggested as symptomatic of sitespecific dance performance. Site-specific choreographer Stephan Koplowitz observes: 'When creating a sitespecific performance one is dealing with multiple levels at once: the architecture of the site, its history, its use, its accessibility. I'm interested in becoming a part of the design and rhythm of the site and amplifying that. This kind of work is not necessarily about big extensions and triple turns, but what is most appropriate for the site The most virtuosic movements might simply be everyone raising their arms together' (Koplowitz, 2003).

15. See Preston-Dunlop (2002).

16. Choreographic devices refer to structuring 'tools' used in the dance-making process such as unison, canon repetition, etc. For a detailed description see Blom and Chaplin (1989).

17. See Hall (1975).

18. This may perhaps explain why a number of sitespecific practitioners choose to create work in derelict sites, the hidden, internal spaces of which may be free from the same degree of prior 'interpretation'.

19. See Bennet, S. (1997). 